\title{
Perdas quantitativas de amendoim nos períodos do dia em sistemas mecanizados de colheita
}

\author{
Pods losses during the mechanical harvesting of peanuts
}

\author{
Fábio Alexandre CAVICHIOLI ${ }^{1}$; Cristiano ZERBATO ${ }^{2}$; Rafael Scabello BERTONHA ${ }^{3}$; \\ Rouverson Pereira da SILVA ${ }^{4}$; Vicente Filho Alves SILVA \\ ${ }_{1}^{1}$ Eng. Agrônomo; Doutorando em Agronomia, FCAV UNESP-Jaboticabal; cavichioli2003@hotmail.com \\ ${ }^{2}$ Autor para correspondência; Eng. Agrônomo; Doutorando em Agronomia; FCAV UNESP-Jaboticabal; \\ Departamento de Engenharia Rural; Laboratório de Máquinas e Mecanização Agrícola; Via de Acesso Prof. \\ Paulo Donato Castellane s/n; 14884-900 - Jaboticabal, SP; cristianozerbato@hotmail.com \\ ${ }^{3}$ Eng. Agrônomo, Doutorando em Agronomia, FCAV UNESP-Jaboticabal; rafabertonha@hotmail.com \\ ${ }^{4}$ Eng. Agrícola; Prof. Dr. Livre Docente; FCAV UNESP-Jaboticabal; rouverson@fcav.unesp.br \\ ${ }^{5}$ Eng. Agrônomo; Doutorando em Agronomia, FCAV UNESP-Jaboticabal; vicentedelta@yahoo.com.br
}

Recebido em: 14-05-2013; Aceito em: 14-04-2014

\begin{abstract}
Resumo
A operação de arranquio mecanizado de amendoim é considerada crítica em função de fatores relacionados à cultura e fatores intrínsecos às máquinas utilizadas, que podem acarretar elevados níveis de perdas. As perdas acontecem no arranquio e no recolhimento do amendoim. Objetivou-se quantificar as perdas em dois períodos de realização da colheita (manhã e tarde), para conjuntos mecanizados. A colheita foi realizada na safra de 2009/2010, em área da fazenda Contendas, localizada no município de Taquaritinga-SP. Foram avaliadas as perdas visíveis, invisíveis e totais no arranquio, o teor de água das vagens no momento do arranquio e do recolhimento, bem como as perdas visíveis totais no recolhimento. Os conjuntos mecanizados utilizados no arranquio e os períodos de colheita não interferiram nas perdas, e o teor de água das vagens não apresentou diferença para o arranquio realizado pela manhã e à tarde. Não foram observadas diferenças entre os tratamentos no recolhimento.
\end{abstract}

Palavras-chave adicionais: arranquio de amendoim; mecanização agrícola; recolhimento de amendoim.

\begin{abstract}
The mechanical uprooting operation by which peanuts are harvested is considered a critical one due to factors related to the crop as well as to factors related to the used equipments which may result in heavy pod losses. These losses occur both during the plant uprooting and that of the picking up of the plants. The objective of this study was to quantify peanut pod losses during harvesting operation being carried out by mechanical equipments during the morning and the afternoon periods. The experiment took place in the crop year of 2009/2010 in a farm located in the municipality of Taquaritinga, state of São Paulo, Brazil. Visible, invisible and total losses during the uprooting operation, pod water content at the plant uprooting and picking up operations and the total visible losses during plant picking up were evaluated. The equipments used for plant uprooting and the harvesting period did not interfere in the amount of losses. Water content was the same for pods harvested during the morning and the afternoon periods. Plant picking up procedures had no significant effects on pod losses, either.
\end{abstract}

Additional keywords: peanut pod uprooting, agricultural mechanization, peanut combining.

Introdução

O amendoim (Arachis hypogaea L.) é considerado, entre as leguminosas, uma das mais importantes culturas, juntamente com o feijão e a soja. Suas sementes proporcionam elevada rentabilidade de óleo de fácil digestão (45 a 50\%), possuindo altos teores de vitaminas (GONÇALVES et al., 2004). Tem como principal diferença em relação às demais, a produção de frutos abaixo da superfície do solo e, devido a esta particularidade, a colheita realiza-se em duas fases distintas, denominadas arranquio e recolhimento (SEGATO \& PENARIOL, 2007).

De acordo com ROBERSON (2009), as perdas na colheita de amendoim são inevitáveis, sendo que, na operação de arranquio, as perdas são maiores, devido ao enfraquecimento do pedúnculo pelo avançado estádio de maturidade, ou pela desfolha prematura causada por doenças, ou, ainda, quando o solo se encontra muito seco e compactado. As perdas no arranquio me- 
canizado desta cultura ocorrem devido à interação de vários fatores relacionados ao cultivo (solo, momento de arranquio, clima, sanidade da cultura, condições de desenvolvimento, plantas daninhas, maturação) e ao maquinário como: projeto, regulagem, manutenção e velocidade (BRAGACHINI \& PEIRETTI, 2008).

No Brasil, estudos sobre perdas na coIheita de amendoim ainda são incipientes, e ainda não existe um padrão recomendável que possa ser adotado como aceitável para estas perdas. Para BRAGACHINI \& PEIRETTI (2008), no momento da colheita, deve-se atentar para as corretas regulagens das máquinas, incluindo a velocidade de deslocamento, além das características do material colhido pela máquina, pois estes fatores podem influenciar na ocorrência de perdas.

Nos Estados Unidos, estudos apontam que as perdas no arranquio de amendoim podem variar de 6 a $20 \%$ da produtividade (WRIGHT \& STEELE, 2006). BEHERA et al. (2008) encontraram perdas totais de $23 \%$ no arranquio mecanizado realizado com teor de água no solo de $8 \%$, constatando que essas perdas diminuíram gradualmente com o aumento do teor água do solo para $10 \%$ e $12 \%$.

A determinação do momento de arranquio do amendoim é fundamental para se atingir máxima produtividade. Por se tratar de planta com hábito de crescimento indeterminado, mesmo quando a colheita ocorre em momento ótimo, o amendoim apresenta vagens em diferentes estádios de maturação (CARLEY et al., 2008; DORNER, 2008) e também variabilidades em seu teor de água no momento do arranquio e do recolhimento.

Considerando-se que as perdas no arranquio e no recolhimento do amendoim podem ser afetadas pela ação das máquinas utilizadas no processo, este trabalho teve como objetivo quantificar as perdas em dois períodos de realização da colheita (manhã e tarde), para conjuntos mecanizados.

\section{Material e métodos}

Tabela 1. Equipamentos utilizados no recolhimento de amendoim. Equipment used to pick up peanut plants.

\begin{tabular}{ll}
\hline \multicolumn{1}{c}{ Trator/Ano de fabricação } & Recolhedora-Trilhadora/Ano \\
\hline Ford 6610, com potência de 60 kW (82 cv) / 1986 & MIAC Double Master I / 2000 \\
Massey Ferguson 292, com potência de 77,2 kW (105 cv) / 1988 & MIAC Double Master I / 1999 \\
Valtra BM 110, com potência de 80,9 kW (110 cv) / 2001 & New Itália Guicol / 2000 \\
\hline
\end{tabular}

As perdas foram classificadas de acordo com as seguintes especificações: visíveis (PVA), invisíveis (PIA) e totais (PTA) do arranquio, que correspondem à soma das perdas visíveis e invisíveis, teor de água das vagens no arranquio
O experimento foi realizado na safra de 2009/2010, na área da Fazenda Contendas, no município de Taquaritinga-SP, localizada nas proximidades das coordenadas geodésicas 2121'54" latitude sul e 48³0'09" longitude oeste, com altitude média de $570 \mathrm{~m}$, apresentando clima Aw, de acordo com a classificação de Koeppen. O solo da área experimental é classificado conforme EMBRAPA (2006), como Latossolo Vermelho, textura argilosa, relevo suave ondulado e declividade média. A área do experimento foi de $3,9 \mathrm{ha}^{-1}$, tendo sido utilizada para a semeadura a cultivar IAC Runner 886.

Os tratamentos, para o arranquio do amendoim, foram constituídos pela combinação de dois períodos de arranquio (manhã e tarde), com dois conjuntos, arrancador-invertedor, totalizando 4 tratamentos, com 5 repetições, em blocos casualizados, em esquema fatorial $2 \times 2$. No arranquio, foram utilizados dois tratores Valtra BM 110 com potência nominal no motor de 80,9 kW (110 cv) a 1.900 rpm, e dois arrancadores-invertedores $2 \times 1$ (duas fileiras $x$ uma leira), sendo um arrancador-invertedor da marca KMC e outro da Agroamérica, ambos montados e acionados pela TDP (tomada de potência) do trator, com rotação de trabalho de $540 \mathrm{rpm}$ e velocidade média de deslocamento de $3,8 \mathrm{~km} \mathrm{~h}^{-1}$.

No recolhimento, 0 delineamento utilizado foi em blocos casualizados, sendo os tratamentos constituídos de quatro conjuntos trator-recolhedora-trilhadora, com 5 repetições (Tabela 1). Esses conjuntos mecanizados trabaIharam com velocidade média de deslocamento de $2,5 \mathrm{~km} \mathrm{~h}^{-1}$, rotação de trabalho na TDP de $540 \mathrm{rpm}$, com capacidade para recolher uma leira (duas fileiras) e largura de trabalho de $1,80 \mathrm{~m}$

Durante o arranquio e o recolhimento, foram determinados o teor de água das vagens (calculado em base úmida), de acordo com 0 método da estufa (BRASIL, 1992), coletando-se amostras após a passagem do arrancadorinvertedor e da recolhedora-trilhadora.

(TAVA), perdas visíveis no recolhimento (PVR) e teor de água das vagens no recolhimento (TAVR). Para coletar esse material, a leira formada após a passagem do arrancador foi cuidadosamente retirada, colocando-se neste local uma armação 
metálica de aproximadamente $2 \mathrm{~m}^{2}(1,11 \times 1,80 \mathrm{~m})$, transversalmente à leira, coletando-se manualmente as perdas visíveis e as perdas invisíveis localizadas até a profundidade de $0,15 \mathrm{~m}$. A definição da largura da armação correspondeu à largura de trabalho do arrancador-invertedor. Para as perdas visíveis no recolhimento (PVR), a armação foi posicionada atrás da recolhedora-trilhadora após a passagem da mesma, em área diferente da amostragem das perdas visíveis no arranquio, sendo então coletadas todas as sementes e vagens que ficaram sobre o solo.

Após a coleta, as vagens foram acondicionadas em sacos de papel e identificadas. Posteriormente, os sacos foram enviados ao laboratório, onde as vagens foram submetidas à lavagem para a retirada da terra aderida ao exocarpo. Sua massa foi mensurada em balança digital, com precisão de $0,01 \mathrm{~g}$. Em seguida, foram colocadas para secar em estufa elétrica, a $105 \pm 3 \stackrel{\circ}{ } \mathrm{C}$, por 24 horas. Após a secagem, a massa das vagens foi novamente determinada, obtendo-se os valores das perdas que foram extrapolados para $\mathrm{kg} \mathrm{ha}^{-1}$, com posterior correção para $8 \%$ de teor de água. Os valores de perdas foram calculados em kg ha-1 e porcentagem em relação à produtividade.

Os dados foram submetidos à análise de variância, pelo teste $F$, e quando pertinente, realizou-se o teste de comparação de médias de Tukey, a $5 \%$ de probabilidade.

\section{Resultados e discussão}

As perdas no arranquio do amendoim não foram afetadas pelos conjuntos mecanizados e períodos de avaliação, bem como pelas interações entre estes fatores que não interferiram nas variáveis de perdas, mesmo apresentando diferenças numéricas expressivas, como para PVA no fator conjunto mecanizado e PIA e PTA para os períodos (Tabela 2). Provavelmente, a não ocorrência de diferença significativa ocorreu devido aos elevados valores dos coeficientes de variação, conforme a classificação dada por PIMENTEL-GOMES \& GARCIA (2002). Segundo CAMPOS et al. (2005), os altos valores encontrados para o coeficiente de variação são justificados pela alta variabilidade das amostras. Os valores médios encontrados de perdas foram: PVA $\left(190,16 \mathrm{~kg} \mathrm{ha}^{-1}\right)$, PIA $\left(174,18 \mathrm{~kg} \mathrm{ha}^{-1}\right)$ e PTA $\left(364,31 \mathrm{~kg} \mathrm{ha}^{-1}\right)$. Estas perdas representam de 3,0 a $5,0 \%$ da produção, e estes valores de perdas podem ser considerados baixos quando comparados com os resultados encontrados na bibliografia, que apontam perdas entre 2,6 e $50,0 \%$ (SANTOS et al., 2013). $\mathrm{O}$ fato de terem ocorrido perdas mais baixas deve-se às condições da lavoura, que foi adequadamente conduzida, bem como aos teores médios de água nas vagens no momento do arranquio, que se situaram próximos dos valores recomendados por SEGATO \& PENARIOL (2007), de 35 a $45 \%$.

Tabela 2 - Perdas visíveis no arranquio (PVA), perdas invisíveis no arranquio (PIA), perdas totais no arranquio (PTA) e teor de água das vagens no arranquio (TAVA). Peanut pod visible losses during plant uprooting (PVA), invisible losses during plant uprooting (PIA), total losses during plant uprooting (PTA) and pod water content during plant uprooting (TAVA)

\begin{tabular}{lcccc}
\hline Fatores & PVA $\left(\mathrm{kg} \mathrm{ha}^{-1}\right)$ & PIA $\left(\mathrm{kg} \mathrm{ha}^{-1}\right)$ & PTA $\left(\mathrm{kg} \mathrm{ha}^{-1}\right)$ & TAVA (\%) \\
\hline Maquinas (M) & & & \\
\hline KMC/BM110 & 227,35 & 190,27 & 385,38 & 47,99 \\
Agroamérica/BM110 & 152,98 & 158,10 & 343,24 & 47,05 \\
\hline Períodos (P) & & & \\
\hline Manhã & 195,43 & 223,85 & 419,23 & 48,16 \\
Tarde & 184,90 & 124,52 & 309,39 & 46,88 \\
\hline Teste F & & & \\
\hline M & $2,02^{\mathrm{ns}}$ & $0,22^{\mathrm{ns}}$ & $0,26^{\mathrm{ns}}$ & $0,26^{\mathrm{ns}}$ \\
H & $0,04^{\mathrm{ns}}$ & $2,11^{\mathrm{ns}}$ & $1,82^{\mathrm{ns}}$ & $0,48^{\mathrm{ns}}$ \\
M x H & $0,02^{\mathrm{ns}}$ & $0,82^{\mathrm{ns}}$ & $0,73^{\mathrm{ns}}$ & $0,08^{\mathrm{ns}}$ \\
\hline CV \% & 61,41 & 87,61 & 49,92 & 8,61 \\
\hline
\end{tabular}

Ausência de letras representa diferença não significativa a 5\% de probabilidade, pelo teste de Tukey; ns: não significativo.

Constata-se, ainda, que o teor de água das vagens no momento do arranquio não foi alterado nos períodos de avaliação, encontrando-se próxi- mos a $45 \%$, valor este observado também em diversos trabalhos enfocando o arranquio mecanizado de amendoim (SANTOS et al., 2013). 
O fator conjunto mecanizado para o recolhimento não interferiu na variável perdas (Tabela 3), apresentando coeficiente de variação muito alto (acima de $30 \%$, de acordo com PIMENTEL-GOMES \& GARCIA, 2002). Essa alta variabilidade tem sido observada, também, em outras culturas, como a cana-de-açúcar (LOPES et al., 1995; SILVA et al., 2008), sendo considerada por estes autores como decorrente da ausência de pleno não controle das condições de colheita e relacionada, portanto, à variabilidade natural do processo.

Tabela 3. Perdas visíveis totais no recolhimento (PVTR) e teor de água das vagens no recolhimento (TAVR). Total visible losses during plant picking up (PVRT), and pod water content during plant picking up (TAVR)

\begin{tabular}{ccc}
\hline Fator - Máquinas & PVTR $\left(\mathrm{kg} \mathrm{ha}^{-1}\right)$ & TAVR $(\%)$ \\
\hline Double Master- I/FORD- 6610 & 257,10 & 12,04 \\
Double Master- I/Massey- 292 & 415,90 & 14,94 \\
Guicol/ BM110 & 164,54 & 11,34 \\
Guicol/ Massey- 292 & 424,96 & 14,94 \\
\hline Teste F & $1,88^{\text {ns }}$ & $2,51^{\text {ns }}$ \\
\hline CV \% & 65,55 & 18,80 \\
\hline
\end{tabular}

Ausência de letras representa diferença não significativa a 5\% de probabilidade, pelo teste de Tukey; ns: não significativo.

Pode-se atribuir o elevado nível de perdas ao tempo de vida dos conjuntos mecanizados, pois as máquinas utilizadas possuíam mais de 10 anos de vida. O tempo de utilização de um equipamento no processo de colheita de amendoim é muito importante devido ao fato de esta ser uma cultura frágil, sendo necessário total cautela; afinal, para se obter as vagens arrancadas, são realizados dois processos: arranquio e recolhimento. Outro fator que pode ter contribuído para as perdas é o teor de água no momento do recolhimento.

Em trabalho de SEGATO \& PENARIOL (2007), as vagens de amendoim e suas ramas (matéria vegetal), após o arranquio, apresentam alto teor de água (entre 35 e $45 \%$ ), reduzindo a matéria vegetal após período médio de secagem de quatro dias, para valores médios de teor de água entre 18,0 e $24,0 \%$. Quando o teor de água da matéria vegetal é muito baixo, as vagens destacam-se da rama no momento do recolhimento da leira, proporcionando maiores perdas. Por outro lado, teores de água mais elevados dificultam o destacamento das vagens da matéria vegetal. A ocorrência de chuvas durante o período de colheita é o principal fator que colabora para o alto teor de água das vagens e matéria vegetal, com consequências diretas sobre as perdas e a qualidade do amendoim, já que o material permanece mais tempo no campo até atingir o teor de água ideal para o recolhimento.

Portanto, pode-se afirmar que parte das perdas no recolhimento, encontradas neste trabalho, deve-se ao fato de o teor de água das vagens estar fora do recomendado na bibliografia (acima de 18 e abaixo de $24 \%$ ), enquanto outra parte se deve, provavelmente, ao fato de os conjuntos mecanizados apresentarem tempo de utilização elevado.

\section{Conclusões}

As perdas visíveis, invisíveis e totais no arranquio, e as perdas visíveis totais no recolhimento não diferiram entre os conjuntos mecanizados nem para os períodos de avaliação (manhã e tarde) para a cultivar IAC Runner 886.

\section{Referências}

BEHERA, B. K.; BEHERA, D.; MOHAPATRA, A. K.; SWAIN, S.; GOEL, A. K. Performance evaluation of a bullock drawn groundnut digger. Environment and Ecology, v.26, n.3, p.12261229, 2008.

BRAGACHINI, M. E.; PEIRETTI, J. Mejoras en la eficiencia de cosecha de maní. Gacetilla de Prensa: 09/2008 - Março 2008. Disponível em: http://www.cosechaypostcosecha.org/data/gacetil las/2008/20080319_mani.asp. Acesso em 2 dez. 2011.

BRASIL. Ministério da Agricultura e da Reforma Agrária. Regras para análise de sementes. Brasilia: SNAD/DNPV/CLAV, 1992. 385p.

CAMPOS, M. A. O.; SILVA, R. P.; CARVALHO FILHO, A.; MESQUITA, H. C. B.; ZABANI, S. Perdas na colheita mecanizada de soja no estado de Minas Gerais. Engenharia Agrícola, Jaboticabal, v.25, n.1, p.207-213, 2005.

CARLEY, D. S.; JORDAN, D. L.; DHARMASRI, L. C.; SUTTON, T. B.; BRANDENBURG, R. L.; BURTON, M. G. Peanut Response to Planting Date and Potential of Canopy Reflectance as an Indicator of Pod Maturation. Agronomy Journal, Madison, v.100, n.2, p.376-380. 2008. 
DORNER, J. W. Relationship between kernel moisture content and water activity in different maturity stages of peanut. Peanut Science, Tifton, v.35, n.2, p.77-80, 2008.

EMBRAPA - Empresa Brasileira de Pesquisa Agropecuária. Centro Nacional de Pesquisa de Solos. Sistema brasileiro de classificação de solos. 2.ed. Rio de Janeiro, 2006. 306p.

GONÇALVES, J. A.; PEIXOTO, C. P.; LEDO, C. A. S. Componentes de produção de amendoim em diferentes arranjos espaciais no Recôncavo Baiano. Revista Brasileira de Oleaginosas e Fibrosas, Campina Grande, v.8, n. 2/3, p.801812, 2004.

LOPES, M. B.; MILAN, M.; COELHO, J. L. D. Qualidade em operações agrícolas mecanizadas na cultura de cana-de-açúcar. Stab: Açúcar, Álcool e Subprodutos, Piracicaba. v.13, p.2630, 1995.

PIMENTEL-GOMES, F.; GARCIA, C. H. Estatística Aplicada a experimentos agronômicos e florestais: exposição com exemplos e orientações para uso de aplicativos. Piracicaba: FEALQ, 2002. 309p.
ROBERSON, G. T. Planting, havesting, and cuing peanuts. In: JORDAN, D. L.; BRANDENBURG, R. L.; BROWN, A. B.; BULLEN, S. G.; ROBERSON, G. T. ; SHEW, B.; SPEARS, J. F. Peanut information 2010. North Carolina: Coop. Ext. Ser. Series AG-331, 2009. p.131-148.

SEGATO, S. V.; PENARIOL, A. L. A cultura do amendoim em áreas de reforma de canavial. In: Segato, S. V.; FERNANDES, C.; SENE PINTO, A. Expansão e renovação de canavial. Piracicaba: Editora CP 2, 2007. p.85-116.

SILVA, R. P.; CORRÊA, C. F.; CORTEZ, J. W.; FURLANI, C. E. A. Controle estatístico aplicado ao processo de colheita mecanizada de cana-deaçúcar. Engenharia Agrícola, Jaboticabal, v.28, n.2, p.292-304, 2008.

SANTOS, E. P.; SILVA, R. P.; BERTONHA, R. S.; NORONHA, R. H. F.; ZERBATO, C. Produtividade e perdas de amendoim em cinco diferentes datas de arranquio. Revista Ciência Agronômica, Fortaleza, v.44, n.4, p.695-702, 2013.

WRIGHT, F. S.; STEELE, J. L. Potential for direct harvesting of peanuts. Peanut Science, Raleigh, v.6, n.1, p.37-42. 2006. 